\title{
ESTUDO DA AUTONOMIA NO CONTEXTO DA EDUCAÇÃO A DISTÂNCIA PARA ESTUDANTES DE UM CURSO DE LICENCIATURA
}

FORTALEZA/CE MAIO/2018

\author{
JOAO CLAUDIO NUNES CARVALHO - IFCE - joaoclaudio@fisica.ufc.br \\ Paulo Nogueira - FGF - paulonogueira@fgf.edu.br \\ Tipo: Investigação Científica (IC) \\ Natureza: Descrição de Projeto em Andamento \\ Categoria: Pesquisa e Avaliação \\ Setor Educacional: EDUCAÇÃO SUPERIOR
}

\begin{abstract}
RESUMO
Na área da educação, cursos a distancia estão sendo oferecidos em diferentes áreas, visando atender demandas de formação profissional e de novos conhecimentos. Ao longo de toda a história, mudanças vêm acontecendo em diversos setores da nossa sociedade, inclusive na área educacional. A fim de suprir essas exigências, as atividades propostas pelos professores precisam ser bem planejadas e requerem, inclusive, estrutura física adequada para sua realização.

No contexto escolar atual, é impensável realizarmos algumas tarefas sem a ajuda de um computador. Pilhas de cadernos, agendas e planilhas de papel foram substituídas por arquivos, que facilitam 0 fechamento de notas, o controle de presenças, a emissão do histórico dos alunos, etc. Provas são elaboradas com o uso de softwares, internet e editores de texto. Temos que reconhecer, porém, em que a presença de alguns recursos tecnológicos deve deixar de ser imprescindível apenas no espaço administrativo e ocupar seu lugar onde será mais útil e mais ricamente aproveitada: a sala de aula.

O Ensino a Distância é considerado por muitos como a educação do futuro, e também não é por menos. Ele chegou para encurtar distâncias, poupar tempo e estar ao alcance de todos. Nossa tecnologia evoluiu, e a maneira que aprendemos e ensinamos não é mais a mesma. $O$ ensino à distância vem crescendo de forma gradual em nosso país. Segundo dados do Censo de 2014, as matrículas somaram 519.839 nos cursos regulamentados totalmente a distância, 476.484 em cursos regulamentados semipresenciais ou disciplinas EAD de cursos presenciais e 2.872 .383 em cursos livres, totalizando 3.868 .706 registros.
\end{abstract}

Palavras-chave: autonomia, ead, licenciatura 


\section{INTRODUÇÃO}

$\mathrm{Na}$ área da educação, cursos a distancia estão sendo oferecidos em diferentes áreas, visando atender demandas de formação profissional e de novos conhecimentos. Ao longo de toda a história, mudanças vêm acontecendo em diversos setores da nossa sociedade, inclusive na área educacional. Tais mudanças, geradas pelo processo de globalização e pelo avanço tecnológico, segundo BELLONI, (2009, p. 3) exigem transformações nos sistemas educacionais, os quais vêm sendo confrontados com novos desafios. Com isso, o papel da educação se transforma e suas estratégias se modificam para atender as novas demandas educativas da sociedade do saber ou da informação.

A fim de suprir essas exigências, as atividades propostas pelos professores precisam ser bem planejadas e requerem, inclusive, estrutura física adequada para sua realização. De acordo com as orientações do Ministério da Educação para o oferta dos cursos a distância, é obrigatório que as instituições de ensino superior tenham laboratórios e bibliotecas, em polos presenciais. Temos que considerar também que os métodos educacionais se modernizaram. No contexto escolar atual, é impensável realizarmos algumas tarefas sem a ajuda de um computador. Pilhas de cadernos, agendas e planilhas de papel foram substituídas por arquivos, que facilitam 0 fechamento de notas, o controle de presenças, a emissão do histórico dos alunos, etc. Provas são elaboradas com o uso de softwares, internet e editores de texto. Temos que reconhecer, porém, em que a presença de alguns recursos tecnológicos deve deixar de ser imprescindível apenas no espaço administrativo e ocupar seu lugar onde será mais útil e mais ricamente aproveitada: a sala de aula.

O Ensino a Distância é considerado por muitos como a educação do futuro, e também não é por menos. Ele chegou para encurtar distâncias, poupar tempo e estar ao alcance de todos. Nossa tecnologia evoluiu, e a maneira que aprendemos e ensinamos não é mais a mesma. O ensino à distância vem crescendo de forma gradual em nosso país. Segundo dados do Censo de 2014, as matrículas somaram 519.839 nos cursos regulamentados totalmente a distância, 476.484 em cursos regulamentados semipresenciais ou disciplinas EAD de cursos presenciais e 2.872 .383 em cursos livres, totalizando 3.868 .706 registros. 


\section{OBJETIVOS}

O presente trabalho tem como objetivo de pesquisa diagnosticar o nível de satisfação dos alunos referente à Educação a Distancia, bem como analisar a construção da autonomia, através do conteúdo das falas dos entrevistados, buscando refletir a experiência dos alunos no Curso de Licenciatura em Matemática da Universidade Aberta do Brasil - UAB, modalidade EAD, evidenciando pontos relevantes de análise sobre a contribuição dessa modalidade, como a qualidade da formação frente a demanda existente e apontar caminhos para a superação das dificuldades encontradas.

\section{REFERENCIAL TEÓRICO}

\subsection{O CONCEITO DE EDUCAÇÃO A DISTANCIA}

A Educação a Distância se dá através de recursos tecnológicos que mediam os processos de ensino-aprendizagem, onde alunos e professores se encontram em tempos e lugares distintos. Por isso é necessário que o processo de ensinoaprendizagem esteja adaptado aos diferentes níveis de conhecimentos dos alunos.

A importância da EaD para CIRIGLIANO é ter a "educação a distancia como modalidade e a educação aberta, como ideal, são caminhos para converter em realidade a aspiração de oferecer a todos o acesso ao saber em todos os níveis".

Este saber do qual o autor acima relata, trata do novo indicador de mudança no cenário educacional, pois o profissional necessita refletir sobre a importância das tecnologias da informação e Comunicação para a Educação. O acelerado aumento de informações que caracteriza o mundo moderno torna o aprendizado um desafio que parece quase inalcançável e, neste aspecto, os velhos modelos de aprendizado nos têm deixado na mão. Vencer tamanho desafio requer um novo pensamento e novos recursos.

\subsection{A AUTONOMIA NA EaD}

Segundo MOREIRA (2014, p. 41) autonomia é um tema abrangente e difícil de ser conceituado objetivamente, pela grande quantidade de aspectos a serem considerados e pelos fatores que podem concorrer para a sua efetividade. Portanto, se faz necessário algumas conceituações quanto ao termo, para embasar o estudo a respeito da autonomia para aprendizagem na educação à distância. 
Trazendo o termo para o contexto da educação, conforme FREIRE (1996, p. 94), a autonomia é um processo de construção e de exercício da liberdade, que ao mesmo tempo se faz responsabilidade particular de cada um, de querer fazer o seu caminho na construção do conhecimento: "[...] É com ela, a autonomia, penosamente construindose, que a liberdade vai preenchendo o "espaço" antes "habitado" por sua "dependência". Sua autonomia que se funda na responsabilidade vai sendo assumida." Neste sentido, pode-se afirmar que autonomia também é a negação e o rompimento de qualquer tipo de dependência, o que é uma deliberação própria.

Segundo WISSMANND et al. (2006), de acordo com LITTLE (1994, p. 431 apud WISSMANND, 2006), a autonomia requer três princípios que dão ênfase a individualidade do aprendiz: agenda pessoal, iniciativa e auto avaliação. O indivíduo autônomo tem de criar uma agenda pessoal que direcione e organize seus estudos; tomar iniciativas modelando sua própria aprendizagem e ter a capacidade de autoavaliar este processo, verificando se obteve bom êxito no mesmo. WISSMANND (ibidem) também afirma que "a autonomia do aprendiz requer não só a aprendizagem, mas aprender a aprender."

Portanto, conclui-se que a autonomia do aprendiz é acima de tudo um produto da interdependência do que da independência. Sendo assim, os aprendizes em EaD também devem ser auxiliados a adquirir autonomia por meio de um processo de interação semelhante à aprendizagem formal. Isto nos traz à tona a importância do papel do professor/ tutor, como mediador desse processo, desmitificando a ideia de que, em EaD, o aluno autônomo aprende sozinho e independe do professor. Esse "aprender a aprender" não está somente para o aluno, mas também para o professor, principalmente em tempos de uma educação mediatizada, imersa no mundo das TIC, cujos atores envolvidos estão em constante contato.

\section{PROCEDIMENTOS METODOLÓGICOS}

Quanto ao modo de abordagem a pesquisa foi de natureza quantitativa, cuja investigação buscou valores, atitudes, motivações, causas e compreensão do problema, através da interpretação de informações objetivas e subjetivas, utilizando-se dos dados numéricos que surgiram da investigação e que, no seu conjunto, trazem respostas à problemática estabelecida e satisfazem ao objetivo da pesquisa

Para estudo e coleta de dados, foram aplicados os seguintes métodos e instrumentos: pesquisa bibliográfica e aplicação de questionário. Toda a metodologia de pesquisa 
visou alcançar o objetivo deste trabalho é diagnosticar a formação da autonomia do sujeito aprendiz no contexto da EaD e quais são as dificuldades e as possibilidades para a construção da autonomia nesse contexto. Caracterizando as interações nos espaços e tempos simultâneos e assíncronos no processo de aprendizagem, tendo em vista que a interação se difere da forma de comunicação do ensino presencial contendo 12 perguntas objetivas, onde o entrevistado tinha a sua disposição quatro opções a escolher: excelente, ótimo, bom, regular e insuficiente, conforme tabela 1 e uma indagação quanto ao querer ser professor, tendo como opções para reposta sim ou não. No que concerne as questões abertas, as principais respostas estão elucidadas nas tabelas 2, 3, 4 e 5 .

Abaixo as perguntas que foram utilizadas na abordagem subjetiva da pesquisa:

01 - O que você compreende por autonomia discente na educação on-line

02 - Você já pensou em desistir deste curso? Cite o principal motivo

03 - Cite aspectos que você considera importantes para uma mediação adequada que contribuam para o desenvolvimento da sua autonomia

04 - Relate experiências positivas e/ou negativas de mediação pedagógica vivenciadas no curso.

O público alvo da pesquisa se deu em uma turma do quinto período do curso de licenciatura em matemática do polo de Juazeiro do Norte da Universidade Aberta do Brasil - UAB. Ressalto ainda que a referida turma atualmente cursa a disciplina de física geral II. O espaço amostral da pesquisa é formado por 38 alunos, destes, 08 ficaram sem responder no questionário objetivo.

No questionário subjetivo todos participaram da pesquisa exceto quanto a pergunta 04 , onde 02 alunos não se manifestaram.

Desta análise, pretende-se descrever de forma concisa e direta como se encontra 0 nível de satisfação dos discentes em relação ao curso, bem como observar como esta ocorrendo o processo de construção da autonomia através do conteúdo das falas dos estudantes em EAD. 


\section{APRESENTAÇÃO E DISCUSSÃO DOS RESULTADOS}

Tendo por base a pesquisa aplicada, observamos de acordo com a tabela 1, que quanto ao nível de excelência, todas as perguntas deixaram a desejar, sendo que o questionamento mais considerado neste nível se deu referente à motivação dos alunos com o curso, onde 05 entrevistados demonstraram estar sentindo-se entusiasmados com as aulas.

Para 05 alunos a interação on-line com o tutor é insuficiente, 14 afirmaram ser regular e 10 consideraram bom. Comparando com o apoio da tutoria presencial (questão D) notamos uma significativa melhora nas respostas dos discentes, onde apenas 04 consideraram excelentes e 08 classificaram como ótimo, a tutorial presencial, totalizando $40 \%$ do alunado, outros 08 disseram bom neste quesito.

Quanto à pergunta $\mathrm{C}$ constatou-se que todos participam e realizam as atividades propostas, entretanto qualificaram com 10 afirmativas para ótimo e 12 para bom, mostrando que os mesmos cumprem com os seus compromissos quando são cobrados. No que diz respeito aos momentos de dúvida dos alunos (questão I) o nível de qualificação com 14 para regular e 07 para insuficiente, o segundo mais defasado na pesquisa. Mesmo assim 12 alunos opinaram como bom o nível de segurança em concluir as tarefas sem a ajuda do tutor e 14 responderam ter certa regularidade nas atividades sem o devido auxílio. Podemos associar a segurança na realização da tarefa quando observamos o item $\mathrm{K}$, e notamos que nenhum dos alunos se qualifica como excelentes em seu nível matemático, 16 se acham bons e para ótimo e regular 07 alunos responderam para ambos as questões. Entretanto, nenhum dos alunos tem insatisfação com sua base matemática, mostrando ser uma turma mediana neste quesito.

$\mathrm{Na}$ questão L, 18 consideram bom como os tutores se preocupam com a aprendizagem dos alunos, 10 responderam ser regular, enquanto que apenas uma pessoa demonstrou ser insuficiente o trato do professor com o aluno neste critério. Em relação ao nível de evasão dos discentes no curso de matemática na modalidade Ead, 20 disseram que ocorre com certa regularidade e 07 responderam ser irrelevante o número de alunos que abandonam o curso. De maneira geral constatamos que os níveis das respostas oscilaram entre bom e regular, isso demonstra certa insatisfação entre os alunos com respeito à interação entre o tutor e os mesmos, bem como na dependência na realização de suas atividades e estudos, mostrando assim que a construção da autonomia ainda não foi adquirida pelos alunos. 
Para finalizarmos as questões objetivas, ainda foi realizada uma indagação direta aos alunos se os mesmos queriam realmente seguir a carreira de docente, tendo em vista ser o curso de licenciatura em Matemática. As respostas dos alunos revelam que realmente 89,5 \% estão motivados com o curso e com a expectativa de ser professor em um dos níveis de educação de nosso país, demonstrando que escolheram vivenciar o curso a fim de obter o título de licenciado para exercer a função a qual almejam serem qualificados.

Analisaremos as questões subjetivas, onde os alunos basearam suas respostas na interpretação individual, em sua convivência com o curso.

Observamos que as respostas dos alunos divergiram ao conceituarem o significado de autonomia discente, sendo que 15 definiram estar atrelado ao compromisso e responsabilidade do estudante, onde o mesmo administra o seu tempo da melhor maneira. 07 acreditam ser a capacidade de buscar seu próprio conhecimento. Ter opinião própria, ser independente, ter uma metodologia própria e inovadora e interagir usufruindo da tecnologia, cada qual ficou com 02 na pesquisa. Para outros autonomia é construir seu conhecimento com auxílio do tutor e demais colegas, 04. Algumas respostas não satisfizeram a pesquisa por serem um tanto desconexas e ambíguas, desta forma foram caracterizadas como sem coerência 04 repostas.

Observamos que as respostas dos alunos divergiram ao conceituarem o significado de autonomia discente, sendo que 15 definiram estar atrelado ao compromisso e responsabilidade do estudante, onde o mesmo administra o seu tempo da melhor maneira. 07 acreditam ser a capacidade de buscar seu próprio conhecimento. Ter opinião própria, ser independente, ter uma metodologia própria e inovadora e interagir usufruindo da tecnologia, cada qual ficou com 02 na pesquisa. Para outros autonomia é construir seu conhecimento com auxílio do tutor e demais colegas, 04

\section{CONSIDERAÇÕES FINAIS}

No que tange ao tema estudado, o entendimento de autonomia por parte dos estudantes diverge, sendo que a maior parte tem por convicção que essa questão está atrelada a responsabilidade do estudante em relação ao curso ou disciplina, uma outra parte acredita que se refere a capacidade de buscar seu próprio conhecimento. E uma pequena parcela compeende autonomia como sendo a capacidade de ter opnião própria, ser independente ou desenvolver uma metodologia individual e inovadora para interações por meio da tecnologia. 
Tendo por definição que ser autônomo na EaD requer sujeitos que interajam entre si, com cooperação e valores compartilhados. Ser autônomo não significa criar suas próprias regras sem respeitar os valores do próximo. O aluno, dentro desse processo, passa a se constituir como um sujeito que também produz conhecimento, tendo o professor como mediador. A separação espacial e temporal se apresenta apenas como um detalhe, pois professor e aluno são co-responsáveis no alcance dos objetivos educacionais, objetivando a construção individual e social do conhecimento, conforme discutido pelos autores ARCÚRIO, FREIRE E LINARD.

De acordo com a pesquisa qualitativa observam-se tanto pontos fortes como ameaças a serem solucionadas. Diante da análise da pesquisa apresentada podemos concluir a dificuldade apresentada pela turma de licenciatura em Matemática da UAB de Juazeiro do Norte em construir a autonomia, pois ainda tem o modelo presencial bem consolidado em sua experiência educacional. Nas falas dos educandos percebemos ainda que os mesmo sentem muito a falta do tutor em sua lida com o curso, fato que não deve ser menosprezado, pois a autonomia depende de todos envolvidos no sistema e vai sendo construído pelo aprendiz com a ajuda das mediações realizadas. Sendo assim a compreensão de autonomia por uma boa parcela da turma de alunos que foi objeto de estudo deste trabalho, não difefere do que é defendido na literatura.

Diante da análise realizada, entendemos que a autonomia é uma característica primordial à vivência e concretização das aprendizagens na EAD. Para que o estudante a desenvolva é necessário que todos os entes envolvidos no curso, motivem os alunos, apresentem metodologias de ensino diferenciadas, mostrem os resultados satisfatórios de outros que já lograram êxito, estabelecer formas de compartilhar suas vivências fazendo com essas retornem a eles como uma forma de transformação de sua realidade. Assim o estudante poderá ter condições de desenvolver esta importante característica.

\section{Referências}

ARCÚRIO, Michelle Salgado Ferreira. Autonomia do aprendiz na educação a distância, 2008. Disponível em: . Acesso em: 11 dez. 2015.

BELLONI, M. L. Educação a distância. 5.ed. São Paulo: Autores Associados, 2009. CIRIGLIANO, Gustavo F. J. Educación a distancia. Buenos Aires: Editorial Docência, 1986. 
DEMO, Pedro. Educar pela pesquisa. Campinas: Autores Associados, 1996.

FERNANDES, J. da Silva. Educação a distância em Anápolis: o ensino a distância e suas possibilidades. Disponível em: http://www.arcos.org.br/artigos/educacao-adistancia-en- anapolis-o-esnsino-a-distancia-e-suas-possibilidades/\#topo. Acesso em 12 de dez. 2015

FREIRE, Paulo. Pedagogia da Autonomia: saberes necessários à prática educativa. Coleção Leitura. São Paulo: Paz e Terra, 1996 (Coleção Leitura)

FUDA, Jane Cristina e MESQUITA, R. A. Santos. A história da EaD no Brasil. Disponível em:< http://conviversidade.blogspot.com.br/p/historia-da-ead-nobrasil.html .Acesso em 11 dez. 2015.

GUISTA, Angela da Silva; Franco, lara Melo. Educação à distância: uma articulação entre a teoria e a pratica. Ed. PUC Minas. Minas Gerais: 2003.

LINARD, M. A autonomia do aprendente e as TIC. Tradução de Maria Luiza Belloni, 2000. Disponível em: . Acesso em 07 dez. 2015. 